\title{
Teacher Effectiveness In A University Classroom
}

\author{
Clarine Sandstrom, PhD, Minot State University, USA
}

\begin{abstract}
A teaching professor in the Department of Teacher Education and Human Performance is charged with the responsibility of preparing candidates for the teaching profession. This responsibility is not to be taken lightly as it affects the education and school success of future children across the United States and around the world. Along with this strong sense of responsibility, comes a real and deep-seeded passion for learning. Through my informal observations of teaching professors, I see commitment and sensitivity to meeting the needs and concerns of candidates. In the process of meeting ongoing responsibilities, and the needs and concerns of candidates and others, time allocated to preparation for courses and maintaining the delicate balance between the art and science of teaching can become diminished. This awareness coupled with experience as an educator of 38 years led me to examine the critical attributes that contribute to teacher effectiveness in a university classroom. I chose to emphasize teacher effectiveness in a university classroom because of place and time in my career as an educator.
\end{abstract}

Keywords: Attributes of teacher effectiveness, Brain-based learning, Building capacity in teacher candidates, Cognitive science, Constructs for effective teaching, Curriculum mapping, Instructional models, Integration, Model schools, Multiple intelligence theory, Professors and instructional strategies, Rigor, relevance, relationship framework, University classrooms and teaching and learning

\section{INTRODUCTION}

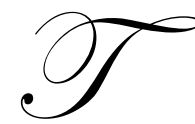

he responsibility of a professor of teacher education is to prepare new teachers. In professors of teacher education I see a will to meet the needs of teacher candidates, but many related duties can get in the way of doing that. After 38 years in education, I therefore set out to define attributes of teacher effectiveness in a university setting, specifically within the context of teacher education.

\section{TEACHER EFFECTIVENESS IN A UNIVERSITY CLASSROOM}

Research on what constitutes effective teaching is accessible through numerous media venues. I am well aware of the research and have much respect for those who have provided the information to us, the teachers. Although teacher effectiveness literature appears to address elementary and secondary educators practicing in the field, there are numerous strategies that university teaching professors can implement. Since the brain is a patternseeking organ, I began to identify those components that make a difference for learners in my university classroom. The following is a glimpse into an effective teacher preparation classroom for undergraduate teacher candidates.

The first component of effectiveness relates to the knowing and understanding of how to balance the art and science of instruction that provides for optimal learning experiences. For me, teaching and learning is about the integration of the biology of learning, teaching strategies, and curriculum development. Focusing on the brain and what we know about the brain and learning is always at the center of planning and implementing appropriate strategies. Proven instructional models, such as 4MAT (McCarthy, 2000) and ITI - Integrated Thematic Instruction, (Kovalik, 1997). Integrating the Multiple Intelligences: New Horizons (Gardner, 1993 \& 2006) theory and strategies have been adapted and modeled to engage candidates by exploring, extending, enriching, and evaluating content and concepts to construct meaning and provide for optimal learning experiences. 
The ARK (Action, Reflection, and Knowledge) Conceptual Framework for the preparation of new teachers at Minot State University incorporates strategies based on cognitive science research, such as Multiple Intelligences Theory and a variety of instructional models such as those cited in this paper. In addition to the implementation of effective teaching models, posing essential questions and aligning content, skills objectives, and assessments are completed through a curriculum mapping process adapted from training and work by Heidi Hayes Jacob (2002). I have come to recognize, understand, and believe that well-designed and mapped curriculum prevents gaps and omissions in the learning process. Curriculum maps, teaching/learning models, and the ARK conceptual framework make up the construct for effective teaching in a university classroom and any classroom where students and teacher interact.

A second component of effectiveness relates to the building of capacity. I learned this from my days as an elementary administrator and my study of Total Leaders by (Schwahn \& Spady, 1998). What I mean by building of capacity is the ability to develop, implement, and sustain productive teacher leadership through empowering teacher candidates in the classroom setting. Building capacity begins with four basic components of thought: (1) understanding the candidates' needs, (2) setting high standards of performance, (3) assessing performance and providing feedback information that supports continuous improvement and growth toward becoming a teacher, and (4) modifying the processes to determine what decisions need to be made to improve processes and results.

I have learned that building and developing capacity involves four elements, along with determination, commitment, and a vision for what could be. The four elements linked to the success of building capacity include Excellence - the desire for and pursuit of the highest quality. For me, it represents a dedication to monitoring and responding constructively to what is done or created by the candidates to ensure they eventually meet or exceed the high standards of knowing and doing. Productivity - the use of available time, resources, technologies, and talent to achieve optimal results. As a future teacher, I want the candidates to recognize and use their "untapped" motivation, creativity, and abilities to generate comprehensive lessons that will increase and enhance student learning. Accountability - taking responsibility for the content and process of teaching and reflective decision-making. Accountability becomes a kind of agreement between candidates and candidates, and candidates and me. Improvement - a commitment to continuously developing and enhancing personal and professional qualities and performance. It means embracing and applying the principle of professionalism now and in the future (Schwahn \& Spady, 1998).

A third component of effectiveness relates to the Rigor, Relevance, and Relationship framework adapted from the literature on Model Schools (2006). This framework has become my vehicle for candidate preparation in elementary education. The rationale for my choice is that candidates become part of the framework for how to organize curriculum and instruction to prepare their future students for the world in which they will be contributors in a global society. My definition of rigor refers to academic learning in which candidates demonstrate a solid, indepth mastery of challenging tasks that develop cognitive skills through reflection, analysis, problem solving, evaluation, and creativity (ARK model). My definition of relevance refers to learning that is interdisciplinary and contextual. Relevance is created through extending and enriching candidate learning. For example, authentic problems or tasks, simulations, service learning, connecting concepts to current issues, and teaching others (peer teaching, pre-practicum teaching in math \& science, and practicum) add relevance to the rigor expectation. Please refer to the frameworks I have adapted from Branigan \& Jones, Model School, 2006 research materials published by International Center for Leadership in Education, Rexford, NY. The frameworks serves teacher candidates and professor well in the preparation of teachers of elementary mathematics (Branigan \& Jones, Model School, 2006). 


\section{Rigor/Relevance Framework}

$\begin{array}{ll}\text { K } & \text { T } \\ \text { N } & \text { A } \\ \text { O } & \text { X } \\ \text { W } & \text { O } \\ \text { L } & \text { N } \\ \text { E } & \text { O } \\ \text { D } & \text { M } \\ \text { G } & \text { Y } \\ \text { E } & \end{array}$

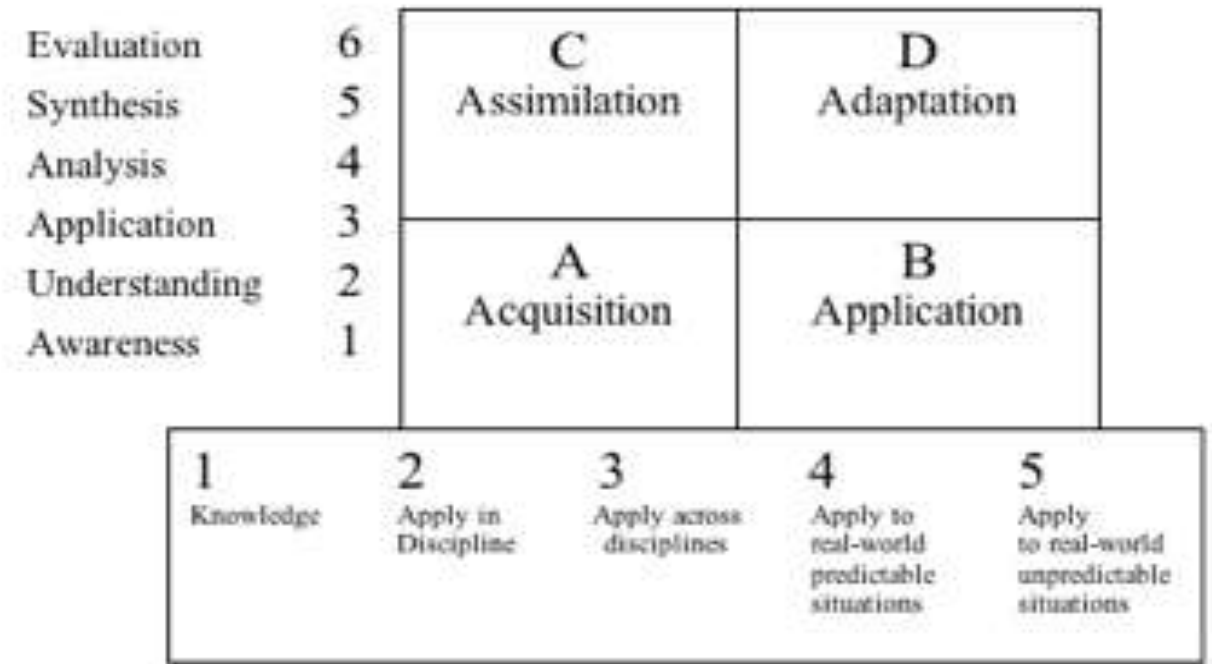

APPLICATION MODEL

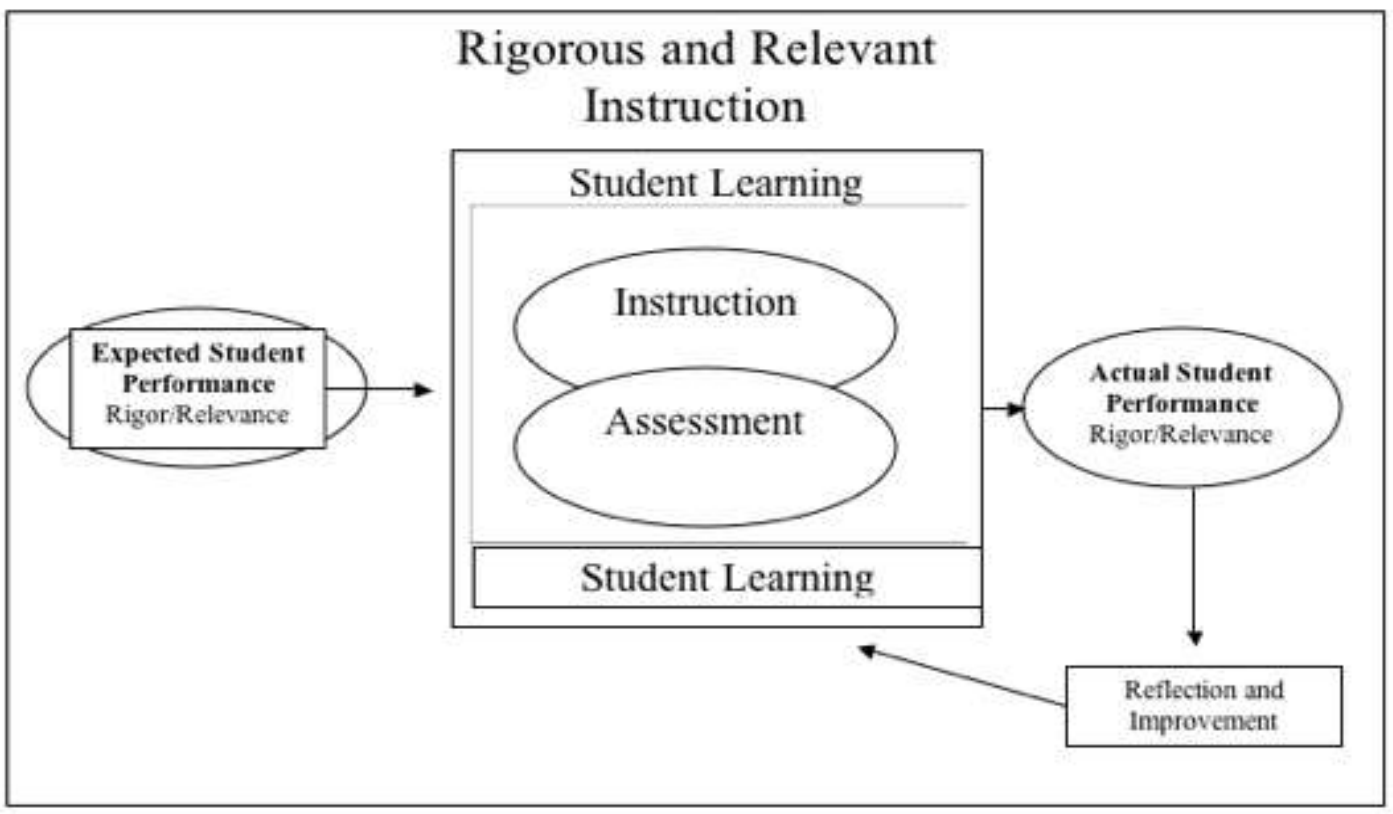

(adapted from the work of Branigan \& Jones, Model School, 2006).

My definition of relationship refers to the support that is provided to candidates from the instructor. When relationship building is important, the candidates and instructor can begin to reflect about current practices and discuss how those might improve relationships. It is my belief that relationships are neither good or bad, but are 
really degrees of qualitative measure that can be changed over time. Using the relationship framework (Branigan \& Jones, 2006) helps candidates identify and recognize the degrees of relationships. Once degrees of relationships are recognized and used, then the candidates begin to think about their relationships with peers, instructor(s), cooperating teachers, supervisors, students, and other adults in their lives. Candidates learn to apply a qualitative measure to the level of those relationships. The framework serves the same purpose for me. Both candidates and professor are able to reflect on their current relationship levels and then decide if changes can be made to improve the relationships. The framework allows for building on the positive aspects of a relationship. For example if I observe a candidate who is isolated, I engage in interventions to engage the candidate and facilitate activities among peers to expand what they know about one another. I believe that everyone in the classroom desires and deserves a high quality personal relationship built on trust and support, which are fundamental in learning. 2006).

The Relationship Framework below was adapted from the work of Branigan \& Jones, Model Schools,

\begin{tabular}{|l|l|}
\hline \multicolumn{2}{|c|}{ Rẹlationship Framework for Elementary Math } \\
Learning Relationships Support for Students \\
\hline \multicolumn{1}{|c|}{} \\
\hline 0.Isolated & $\begin{array}{l}\text { Candidates feel significant isolation from the instructor. Students lack } \\
\text { any emotional, social connection to peers and instructor. }\end{array}$ \\
\hline 1.Known & $\begin{array}{l}\text { Candidates are known by others; frequently called by name. The } \\
\text { instructor knows students, their interests, aspirations and challenges. } \\
\text { Students are known by peers that they interact with in class. }\end{array}$ \\
\hline 2.Receptive & $\begin{array}{l}\text { Candidates have contact with peers and the instructor in multiple settings. } \\
\text { The instructor exhibits positive behaviors of "being there" that show } \\
\text { genuine interest and concern. }\end{array}$ \\
\hline 3.Reactive & $\begin{array}{l}\text { The instructor provides help to candidates when requested, but support } \\
\text { may be sporadic and inconsistent among support groups. }\end{array}$ \\
\hline 4.Proactive & $\begin{array}{l}\text { The instructor takes an active interest in a candidate's success. Instructor } \\
\text { takes initiative to show interest and provide support. Candidates express } \\
\text { verbal commitment for ongoing support and validate this commitment } \\
\text { with their actions. }\end{array}$ \\
\hline 5. Sustained & $\begin{array}{l}\text { There is extensive, ongoing, persuasive and balanced support from the } \\
\text { instructor that is consistent and sustained over time. }\end{array}$ \\
\hline $\begin{array}{l}\text { 6.Mutually } \\
\text { Beneficial }\end{array}$ & $\begin{array}{l}\text { This is the highest level of relationships, where candidates enjoy high } \\
\text { levels of support and also support others in a mutually beneficial learning } \\
\text { relationship. }\end{array}$ \\
\hline
\end{tabular}

\section{CONCLUSION}

An effective university professor recognizes that empowerment of teacher candidates within the classroom is a prerequisite to consistent quality and productivity (Glasser, 1994). Understanding this concept allows for making learning opportunities available for everyone and insists that all participants are able to demonstrate highlevel outcomes. The investment in building capacity is really the essence of effective teacher qualities and strategies, and the result is high performing, productive new teachers. 


\section{REFERENCES}

1. Branigam, H. M. \& Jones, Richard D., (2006). Leadership for rigor/relevance/relationships (Model Schools). Rexford, NY: International Center for Leadership in Education.

2. Gardner, H., (1993 \& 2006). Multiple intelligences: New horizons. NY: Basic Books.

3. Glasser, W., (1994). The control theory manager. New York: HarperCollins.

4. Jacob, H. H., (2002). Advanced curriculum mapping: Unpacking assessment data to improve student performance. Arlington, VA: ASCD.

5. Kovalik, S. (1997). Integrated thematic instruction: The model, $3^{\text {rd }}$. Ed. Kent, WA: Susan Kovalik \& Associated.

6. $\quad$ McCarthy, B. (2004). 4MAT training program. Wauconda, IL: About Learning, Inc.

7. Minot State University (2006-2008). Undergraduate catalog: Teacher education, elementary education. Minot, ND: MSU, p. 162-164.

8. Schwahn, V. J., \& Spady, W. G., (1998). Total leaders: Applying the best future-focused change strategies to education. Arlington, VA: ASCD.

\section{$\underline{\text { NOTES }}$}


NOTES 